\title{
Article
}

\section{Oxygen affinity: the missing link enabling prediction of proton conductivities in doped barium zirconates}

Yoshihiro Yamazaki, Akihide Kuwabara, Junji Hyodo, Yuji Okuyama, Craig A.J. Fisher, and Sossina M Haile Chem. Mater., Just Accepted Manuscript • DOI: 10.1021/acs.chemmater.0c01869 • Publication Date (Web): 30 Jul 2020

Downloaded from pubs.acs.org on July 31, 2020

\section{Just Accepted}

"Just Accepted" manuscripts have been peer-reviewed and accepted for publication. They are posted online prior to technical editing, formatting for publication and author proofing. The American Chemical Society provides "Just Accepted" as a service to the research community to expedite the dissemination of scientific material as soon as possible after acceptance. "Just Accepted" manuscripts appear in full in PDF format accompanied by an HTML abstract. "Just Accepted" manuscripts have been fully peer reviewed, but should not be considered the official version of record. They are citable by the Digital Object Identifier (DOI®). "Just Accepted" is an optional service offered to authors. Therefore, the "Just Accepted" Web site may not include all articles that will be published in the journal. After a manuscript is technically edited and formatted, it will be removed from the "Just Accepted" Web site and published as an ASAP article. Note that technical editing may introduce minor changes to the manuscript text and/or graphics which could affect content, and all legal disclaimers and ethical guidelines that apply to the journal pertain. ACS cannot be held responsible for errors or consequences arising from the use of information contained in these "Just Accepted" manuscripts. 


\title{
Oxygen affinity: the missing link enabling prediction of proton conductivities in doped barium zirconates
}

\author{
Yoshihiro Yamazaki, ${ }^{1,2 *}$ Akihide Kuwabara, ${ }^{3}$ Junji Hyodo, ${ }^{2}$ Yuji Okuyama, ${ }^{4}$ Craig A.J. \\ Fisher, ${ }^{3}$ and Sossina M. Haile ${ }^{5,6}$ \\ 1 Kyushu University Platform of Inter/Transdisciplinary Energy Research (Q-PIT), \\ Kyushu University, 744 Motooka, Fukuoka 819-0395, Japan \\ 2 INAMORI Frontier Research Center, Kyushu University, 744 Motooka, Fukuoka \\ 819-0395, Japan \\ 3 Nanostructures Research Laboratory, Japan Fine Ceramics Center, 2-4-1 Mutsuno, \\ Atsuta-ku, Nagoya, 456-8587, Japan \\ 4 Department of Environmental Robotics, University of Miyazaki, 1-1 \\ Gakuenkibanadai-nishi, Miyazaki 889-2192 Japan \\ 5 Materials Science, California Institute of Technology, 1200 E. California Blvd., \\ Pasadena, CA 91125, USA \\ 6 Department of Materials Science and Engineering, Northwestern University, 2220 \\ Campus Drive, Evanston, IL 60208, USA \\ * corresponding author: yamazaki@ifrc.kyushu-u.ac.jp
}

\begin{abstract}
Proton-conducting oxides, specifically doped barium zirconates, have garnered much attention as electrolytes for solid-state electrochemical devices operable at intermediate temperatures $\left(400-600^{\circ} \mathrm{C}\right)$. In chemical terms, hydration energy, $E_{\mathrm{hyd}}$, and proton-dopant association energy, $E_{\text {as }}$, are two key parameters which determine whether an oxide exhibits fast proton conduction, but to date ab initio studies have for the most part studied each parameter separately, with no clear correlation with proton conductivity identified in either case. Here, we demonstrate that the oxygen affinity, $E_{\text {O.dopant, }}$ defined as the energy released when an oxide ion enters an oxygen vacancy close to a dopant atom, is the missing link between these two parameters and correlates well with experimental proton conductivities in doped barium zirconates. Ab initio calculations of point defects and their complexes in Sc-, In-, Lu-, Er-, Y-, Gd-, and Eu-doped barium zirconates are used to determine $E_{\mathrm{hyd}}, E_{\mathrm{as}}, E_{\mathrm{O} \text {.dopant }}$, and the hydrogen affinity, $E_{\mathrm{H} \text {.host }}$, of each system. These four energy terms are related by $E_{\text {hyd }}=E_{\text {O.dopant }}+2 E_{\text {H.host }}+2 E_{\text {as. }}$. Complementary impedance spectroscopy measurements reveal that the stronger the calculated oxygen affinity of a system, the higher its proton conductivity at $350{ }^{\circ} \mathrm{C}$. Although the proton trapping site is also an important factor, the results show that oxygen affinity is an excellent predictor of proton conductivity in these materials.
\end{abstract}




\section{Introduction}

Fast proton conduction in perovskite-type solid electrolytes e.g., yttrium- or scandium-doped barium zirconate, ${ }^{1-3}$ can be exploited in a number of environmentally friendly devices such as solid oxide fuel cells and electrolyzers, with lower operating temperatures than their oxide-ion conducting counterparts. Proton conduction in these materials requires acceptor doping followed by hydration in moist atmosphere. In $\mathrm{BaZrO}_{3}$ substituting some fraction of tetravalent host ions with trivalent dopants generates oxide-ion vacancies according to $2 C_{V_{0}}=C_{\mathrm{M}}$, where $C_{V_{0}}$ and $C_{\mathrm{M}}$ are the volumetric oxygen vacancy and acceptor dopant $(\mathrm{M})$ concentrations, respectively. Ideally, hydration occurs according to the reaction (in Kröger-Vink notation)

$$
\mathrm{H}_{2} \mathrm{O}_{(g)}+V_{\mathrm{O}}^{\bullet \bullet}+\mathrm{O}_{\mathrm{O}}^{\times} \leftrightarrow 2 \mathrm{OH}_{0}^{\bullet}
$$

where $V_{0}^{\bullet}$ is an oxide-ion vacancy, $\mathrm{O}_{0}^{\times}$is an oxide ion on an oxygen site, and $\mathrm{OH}_{0}$ represents a hydroxyl group formed upon proton incorporation, as the proton is always associated with an oxygen atom. Once incorporated, the proton can migrate from one oxygen atom to the next, resulting in macroscopic proton transport. High crystal symmetry, large molar volumes, and large anion coordination numbers, as occur in the case of barium zirconate, are known to favor high proton conductivity. ${ }^{2,4}$

As with all charge carriers, the proton conductivity, $\sigma_{\mathrm{H}}$, is the product of the proton concentration $\left(C_{\mathrm{H}}\right)$ and the proton diffusivity $\left(D_{\mathrm{H}}\right)$ :

$$
\sigma_{\mathrm{H}}=F^{2} C_{\mathrm{H}} D_{\mathrm{H}} / R T
$$

where $F$ is Faraday's constant, $R$ is the gas constant, and $T$ is temperature. Attaining a high conductivity in a given host oxide, and in barium zirconate in particular, is thus a matter of selecting the optimal dopant that results in both high proton concentration and high proton diffusivity within the desired temperature range. The challenge in finding the optimum dopant for a host oxide to produce high proton conductivity is that $C_{\mathrm{H}}$ and $D_{\mathrm{H}}$ exhibit opposite trends as a function of temperature, with the overall behavior strongly dependent on the particular host-dopant combination.

At a given temperature, $C_{\mathrm{H}}$ can be calculated from the hydration entropy, $\Delta S_{\text {hyd }}$; hydration enthalpy, $\Delta H_{\text {hyd }}$; and water partial pressure, $p_{\mathrm{H}_{2} \mathrm{O}}$, according to

$$
C_{\mathrm{H}}=\left[C_{0} C_{V_{0}} p_{\mathrm{H}_{2} \mathrm{O}} \exp \left(\Delta S_{\mathrm{hyd}} / R\right) \exp \left(-\Delta H_{\mathrm{hyd}} / R T\right)\right]^{1 / 2},
$$

where $C_{\mathrm{O}}$ is the oxide-ion concentration. ${ }^{4,5}$ Proton-conducting oxides generally have a negative hydration enthalpy, giving higher proton concentrations at lower temperatures. Proton diffusivity, on the other hand, is higher at high temperature, as a result of weakened trapping by acceptor dopants, in the dilute limit giving

$$
D_{\mathrm{H}}=D_{0} \exp \left(-E_{\mathrm{a}} / R T\right) /\left\{\left(1+C_{\mathrm{M}, \text { free }} A \exp \left(-E_{\mathrm{as}} / R T\right)\right\},\right.
$$

where $D_{0}$ and $E_{\mathrm{a}}$ are the pre-exponential factor and activation energy, respectively, for proton diffusion, $E_{\mathrm{as}}$ is the proton-dopant association energy, typically negative as proton 
and acceptor are attracted to each other, $A$ is a constant related to the association entropy, and $C_{\mathrm{M} \text {.free }}$ is the concentration of dopant atoms not involved in proton trapping. ${ }^{6}$ These five parameters depend on the nature of both the host material and the dopant, with $C_{\mathrm{M} \text {.free }}$ additionally depending weakly on the extent of hydration. Thus, the situation in proton-conducting oxides is more complex than that of oxide-ion conductors, in which the concentration of charge carriers (oxide-ion vacancies) is almost constant against temperature.

Because of its complexity, the critical parameters determining hydration and proton trapping have been discussed separately based on results of experiment and/or theoretical modeling. Hydration enthalpies have been measured from thermogravimetry experiments for Y-, In-, and Gd-doped $\mathrm{BaZrO}_{3},{ }^{1,7-11}$ and other doped systems such as $\mathrm{BaCeO}_{3},{ }^{1,12-14}$ $\mathrm{BaSnO}_{3},{ }^{15,16} \mathrm{BaTiO}_{3},{ }^{1,}{ }^{17} \mathrm{BaFeO}_{3},{ }^{18,}{ }^{19} \mathrm{SrCeO}_{3},{ }^{1,20,21} \mathrm{SrZrO}_{3},{ }^{1,21} \mathrm{SrTiO}_{3},{ }^{1} \mathrm{SrHfO}_{3},{ }^{1}$ $\mathrm{LaYbO}_{3},{ }^{22-24} \mathrm{LaScO}_{3},{ }^{22,} 24,{ }^{25} \mathrm{LaYO}_{3},{ }^{22,}{ }^{23} \mathrm{LaInO}_{3},{ }^{22,}{ }^{23} \mathrm{LaAlO}_{3},{ }^{22}$ rare-earth oxides, ${ }^{26}$ rare-earth tin oxides, ${ }^{27}$ and rare-earth niobates. ${ }^{28}$ These range from -22 to $-212 \mathrm{kJmol}^{-1}$ depending on how the hydration thermodynamics are defined, the temperature range, and the type of host and dopant. The majority of ab initio calculations of hydration enthalpy have been for those of doped barium zirconates, with values ranging from 44 to -108 $\mathrm{kJmol}^{-1}$ depending on the configuration of dopant, oxygen vacancy, and proton. ${ }^{29-32} \mathrm{With}$ respect to proton trapping, all five terms have been determined experimentally for $20 \mathrm{at} \%$ $\mathrm{Y}$-doped $\mathrm{BaZrO}_{3}$, with activation and association energies of 0.17 (endothermic) and $-0.30 \mathrm{eV}$ (exothermic), respectively. ${ }^{6}$ In agreement with experiment, ab initio calculations have shown that the association energies for calcium zirconates, barium zirconates, and barium stannates are, in all cases, negative. ${ }^{33-37}$

Plots of calculated trapping energies against dopant radius turn out to be volcano shaped as a result of the most energetically favorable trapping site for protons switching from $1^{\text {st }}$ to $2^{\text {nd }}$ nearest neighbors between In and Y. ${ }^{35}$ An earlier study combining NMR and $a b$ initio calculations probed the proton occupancies of the $1^{\text {st }}$ and $2^{\text {nd }}$ nearest neighbors of $Y$ dopants in $\mathrm{BaZrO}_{3}$, confirming the trapping of protons near dopant atoms. ${ }^{38}$ Despite these efforts, no overriding principle for selecting the dopant that maximizes the product of proton concentration and diffusivity for a given host oxide has yet been identified, creating a challenge for the development of proton-conducting solids. ${ }^{39}$

In this paper we develop an ab initio computational framework for predicting proton conductivities in doped barium zirconates at intermediate temperatures, based on the oxygen affinity of an oxygen vacancy adjacent to a dopant atom, which forms a link between $E_{\text {as }}$ and $\Delta H_{\text {hyd }}$. Barium zirconate was chosen as the host material because of its technological relevance ${ }^{2,4}$ and because its simple cubic unit cell renders the treatment of a large number of defect configurations computationally tractable. Sc, In, Lu, Er, Y, Gd, and Eu were chosen as trivalent acceptor dopants for inducing proton conductivity in the barium zirconate crystal bulk. Their ionic radii range from $0.745 \AA$ to $0.947 \AA$ (in 6-fold coordination), and all are larger than the host B-site cation, Zr, which has a radius of $0.72 \AA .{ }^{40}$ Calculations were carried out at $0 \mathrm{~K}$. The effect of finite temperatures and pressures are not considered in the present study; vibrational entropy effects ${ }^{29}$ were not taken into account because 
they make only a small contribution to the overall energy but exact a high extra computational cost.

\section{Methodology}

2.1. Theoretical modeling. Ab initio total energy calculations were carried out using the projector augmented wave (PAW) method ${ }^{41,42}$ as implemented in the VASP code ${ }^{44-46}$ exchange-correlation interactions treated with the generalized gradient approximation (GGA) as parameterized by Perdew, Burke, and Ernzerhof (PBE). ${ }^{43}$ Configurations of valence electrons and radial cut-offs of the PAW potentials used are summarized in Supporting Information Table S1. For lanthanide elements, which include $4 f$ valence electrons, the GGA $+U$ method was used ${ }^{47}$ with $U$ for the $4 f$ orbitals set to $5.4 \mathrm{eV}$ in all cases. ${ }^{48,49}$ As the dynamical stability of cubic $\mathrm{BaZrO}_{3}$ has been reported to be sensitive to the type of exchange-correlation potential used, ${ }^{29,63,64}$ we performed preliminary calculations to confirm that our method correctly predicts the cubic perovskite structure to be the ground state of $\mathrm{BaZrO}_{3}$. Details are provided in Supporting Information.

The unit cell of $\mathrm{BaZrO}_{3}$ was fully optimized with a planewave cut-off energy of $500 \mathrm{eV}$ using a $6 \times 6 \times 6 \mathrm{k}$-point mesh in the first Brillouin zone based on the Monkhorst-Pack scheme ${ }^{50}$ until residual forces were less than $0.02 \mathrm{eV} / \AA$. The optimized lattice constant of $\mathrm{BaZrO}_{3}$ obtained using this method was $4.235 \AA$, which is about $1 \%$ larger than the experimental value of $4.1943 \AA .{ }^{51}$ This difference is within the normal accuracy of GGA-PBE calculations. For defect calculations, supercell models containing $5 \times 5 \times 5$ unit cells ( 625 atoms) were constructed from the optimized unit cell.

After introducing a given defect or defect complex, all atomic positions in the supercell were relaxed until residual forces were less than $0.02 \mathrm{eV} / \AA$ with a cut-off energy of $400 \mathrm{eV}$ at fixed volume. Only the $\Gamma$ point was used for $k$-point sampling in these calculations.

Defects considered in this study included each kind of trivalent dopant $\left(\mathrm{M}^{3+}\right)$ substituted for a $\mathrm{Zr}^{4+}$ ion $\left(\mathrm{M}_{\mathrm{Zr}}^{\prime}\right)$, an interstitial proton $\left(\mathrm{OH}_{\mathrm{O}}^{\circ}\right)$, and pairs of dopant and protonated oxygen $\left(\left(\mathrm{M}_{\mathrm{Zr}} \mathrm{OH}_{\mathrm{O}}\right)^{\times}\right)$, the latter corresponding to a trapped-proton model with two point defects in the same supercell. Trapped-proton models with different distances between the dopant and proton were constructed to identify the deepest trapping well.

Defect formation energies $\left(E_{\mathrm{f}}\right)$ were calculated according to ${ }^{52}$

$E_{\mathrm{f}}\left(D^{q}\right)=E_{\text {sup }}\left(D^{q}\right)-E_{\text {sup }}($ perf $)-\sum_{i} \Delta n_{i} \mu_{i}+q\left(E_{\text {fermi }}+E_{\mathrm{VBT}}\right)$

where $E_{\text {sup }}\left(D^{q}\right)$ and $E_{\text {sup }}$ (perf) are total energies of the supercell including the defect, $D^{q}$, of charge state $q$, and of the perfect (defect-free) supercell, respectively; $\Delta n_{i}$ is the difference in the number of component atom $i$ between the defective and perfect supercells; $\mu_{i}$ is the chemical potential of atom $i$; and $E_{\mathrm{VBT}}$ and $E_{\text {fermi }}$ are the energy of the valence band top (VBT) and the Fermi energy in the band gap measured from the VBT, respectively (Supporting Information Figure S1). In the case of supercells containing charged defects, errors caused by electrostatic interactions from periodic boundary images were corrected using Kumagai and Oba's extension ${ }^{53}$ to the method proposed by 
Lany and Zunger. ${ }^{54}$ Further details of the defect formation energy calculations are explained in Supporting Information.

Proton-dopant association energies, $E_{\text {as }}$, were calculated as the difference between the total energy of a $5 \times 5 \times 5$ supercell containing a proton in the vicinity of a dopant atom, and the sum of energies of supercells containing a proton and dopant atom in isolation. The most energetically stable proton position for each type of dopant was determined by placing the proton on one of 16 different positions near the dopant (Supporting Information Figure S3), and allowing all atoms to relax to their low-energy positions while holding the cell volume constant.

The dopant concentrations in these models represent the dilute limit case. Although clustering of dopant species can impact the proton-dopant association energetics, ${ }^{55,56}$ repulsive interactions between dopants render the probability of encountering dopant-dopant nearest neighbors at moderate dopant concentrations low. ${ }^{36}$ Thus, such clusters are unlikely to play a major role in the overall thermodynamic and transport properties of doped barium zirconate when the dopant content is optimal. This is consistent with the insensitivity of the hydration thermodynamics to dopant concentration observed experimentally. ${ }^{9}$ Here it is found that the dilute model successfully captures the essential features of fast proton-conducting oxides, as verified by the conductivity measurements presented below.

2.2. Experimental methods. Powders of nominal composition $\mathrm{BaZr}_{0.8} \mathrm{Sc}_{0.2} \mathrm{O}_{3-\delta}$, $\mathrm{BaZr}_{0.8} \mathrm{In}_{0.2} \mathrm{O}_{3-\delta}, \mathrm{BaZr}_{0.8} \mathrm{Lu}_{0.2} \mathrm{O}_{3-\delta}, \mathrm{BaZr}_{0.8} \mathrm{Er}_{0.2} \mathrm{O}_{3-\delta}$, and $\mathrm{BaZr}_{0.8} \mathrm{Gd}_{0.2} \mathrm{O}_{3-\delta}$ were synthesized using a chemical solution method. ${ }^{2}$ Compacts $(20 \mathrm{~mm}$ in diameter and $1 \sim 2 \mathrm{~mm}$ in thickness) were prepared by isostatic cold pressing, and these were then sintered at $1600{ }^{\circ} \mathrm{C}$ for $30 \mathrm{~h}$ in air to obtain samples of greater than $92 \%$ theoretical density. X-ray diffraction confirmed that a single cubic perovskite phase was formed in all cases, with the lattice constant increasing with increasing dopant ion radius. For impedance spectroscopy experiments, each dense pellet was polished to attain mirror-like surfaces and a thickness of $0.45-0.5 \mathrm{~mm}$. For electrical measurements, $650 \mathrm{~nm}$ silver films were deposited on both surfaces of a pellet by DC sputtering with a Sanyu Electron SC-701HMCII sputter coater. Each sample was then sandwiched between silver mesh current collectors and annealed at $900{ }^{\circ} \mathrm{C}$ for $2 \mathrm{hrs}$ under air, creating a structure with interconnected porous silver electrodes firmly adhered to the silver current collectors. Impedance measurements were performed using a Hioki IM3536 LCR meter over the frequency range $4 \mathrm{~Hz}$ to $8 \mathrm{MHz}$ (and voltage amplitude of $100 \mathrm{mV}$ ). Pellet samples were heated to $750{ }^{\circ} \mathrm{C}$ under dry, high-purity nitrogen gas containing less than $1 \mathrm{ppm}$ oxygen, and held there for an hour to dehydrate and remove any surface carbonates. The gas was then saturated with water $\left(\mathrm{pH}_{2} \mathrm{O}=0.023 \mathrm{~atm}\right)$ and held under these conditions for $1 \mathrm{hr}$ to protonate the pellets. The conductivity was measured upon cooling from 750 to $30{ }^{\circ} \mathrm{C}$ at $10^{\circ} \mathrm{C} / \mathrm{min}$ and recorded at several temperatures with an equilibration time of $1 \mathrm{hr}$ at $650{ }^{\circ} \mathrm{C}$ and $15 \mathrm{~min}$ at lower temperatures. The bulk conductivity was differentiated from the grain boundary conductivity at $406^{\circ} \mathrm{C}$ and below. Measurements were repeated at least twice to confirm reproducibility. Nyquist plots of the impedance spectra exhibited well-resolved arcs. The data were analyzed in terms of an equivalent circuit model in which (depending on the temperature regime) distinct RQ subcircuits were used to 
represent the grain interior, grain boundary, and electrode regions. Here, $\mathrm{R}$ is an ideal resistor with $Z_{\mathrm{R}}=R$ and $\mathrm{Q}$ is a constant phase element with $\mathrm{Z}_{\mathrm{Q}}=\left(Y(j \omega)^{n}\right)^{-1}$, where $j$ is $\sqrt{ }-1$, $\omega$ is the frequency, and $Y$ and $n$ are constants, with $0<n<1$, with $n$ ranging from 0.83 to 1 in the case of the grain interior.

\section{Results and discussion 3.1. Energy calculations.}

The energy terms evaluated in our analytical framework and their corresponding chemical equations are listed in Table 1 . These are the hydration energy, $E_{\text {hyd }}$, the dopant-proton association energy, $E_{\mathrm{as}}$, the oxygen affinity, $E_{\mathrm{O} \text {,dopant }}$, the hydrogen affinity, $E_{\mathrm{H} . h o s t}$, and the hydration energy of free (non-trapped) protons, $E_{\text {hyd.free, }}$ Here, the hydration energy, $E_{\text {hyd }}$, is defined as the change in system energy upon introduction of a water molecule, which dissociates into a hydroxyl group and a proton, and can be thought of as the zero-kelvin, one-proton limit of $\Delta H_{\text {hyd }}$, the experimentally measurable amount of hydration of the bulk crystal. The hydroxyl group becomes incorporated at an oxygen vacancy site near a trivalent dopant, in other words, at a trapped oxygen vacancy site, ${ }^{29,36}$ and similarly the proton is incorporated at an oxygen site near another dopant. Thus, when calculating $E_{\text {hyd }}$, we consider the lowest energy defect configuration before and after hydration. Similarly, for the calculation of the dopant-proton association energy, $E_{\mathrm{as}}$, we use the most stable configuration/position of the proton. The hydrogen affinity, $E_{\text {H.host }}$, is a property of the undoped host oxide $\mathrm{BaZrO}_{3}$, and is found to be $0.050 \mathrm{eV}$.

Values of these energies were calculated using DFT energies of their component product and reaction terms for each of the candidate dopants. Figure 1 shows plots of $E_{\text {as }}$ vs distance between dopant atom and proton, together with schematics of the local structures around systems with the proton on $1^{\text {st }}$ and $2^{\text {nd }}$ nearest proton (NP) sites. In all cases, the association energy is greater when the proton is in close proximity to the dopant, out to the $11^{\text {th }}$ NP site (Figure 1b).

The proton-dopant association energies in Figure $1 \mathrm{~b}$ show that the dopants examined fall into one of two categories. For smaller dopants ( $\mathrm{Sc}$, In, and $\mathrm{Lu}$ ), trapping is deepest when the proton is on a $1^{\text {st }} \mathrm{NP}$ site. Larger dopants (Er, Y, Gd, and Eu), in contrast, produce the strongest trapping when the proton is on a $2^{\text {nd }} \mathrm{NP}$ site. These observations are consistent with a previous ab initio study examining dopants $\mathrm{Ga}, \mathrm{Sc}$, In, $\mathrm{Y}$, and Gd. ${ }^{35}$ Direct experimental evidence for proton occupation of the $2^{\text {nd }} \mathrm{NP}$ site in Y-doped $\mathrm{BaZrO}_{3}$ was obtained using dynamic nuclear polarization nuclear magnetic resonance. ${ }^{38}$ The experimentally measured association energy of $20 \% \mathrm{Y}$-doped $\mathrm{BaZrO}_{3}$ is $-0.30 \mathrm{eV}^{6}$, and the slight disagreement with the computational value of $-0.22 \mathrm{eV}$ is attributed largely to the differences in dopant concentration and temperature. Figure 1 shows that within the group of smaller dopants the magnitude of the association energy diminishes substantially between the $1^{\text {st }}$ and $2^{\text {nd }} \mathrm{NP}$ sites and then levels off for $3^{\text {rd }} \mathrm{NP}$ sites and beyond. The association energies obtained for the larger dopants are less convergent, with non-negligible differences in values between different dopant species and greater number of local minima at relatively large distances from the dopant. Long-range coulombic interactions and lattice distortion are likely responsible for the non-zero association energies at the longest $\mathrm{M}-\mathrm{H}$ distances of about $8 \AA$ considered in the analysis. 
Calculated hydration energies exhibit a trade-off relationship with proton-dopant association energies, as seen in Figure 2a. Under the reasonable assumptions that the activation energy, $E_{\mathrm{a}}$, for proton diffusion, the pre-exponential factor, $D_{0}$, the concentration of dopant atoms not involved in proton trapping, $C_{\mathrm{M} \text {.free, }}$, and the association entropy-related constant $A$ in eq. (4) and the hydration entropy in eq. (3) are, to a first approximation, independent of the type of dopant and dopant-proton distance, the ideal fast proton-conducting oxide would be a material that has a larger (more negative) hydration energy and smaller (less negative) association energy to maximize the proton concentration and diffusivity simultaneously, resulting in enhanced proton conductivity at intermediate temperatures. Such materials should locate in the bottom-right of the plot of hydration energy vs proton-dopant association energy in Figure 2a. When the hydration energy is greater, the association energy also becomes larger, resulting in a trade-off relationship between proton concentration and proton diffusivity depending on the choice of dopant.

The hydration reaction, with energy $E_{\text {hyd }}$, can be conceptualized as the sum of three (virtual) reactions, the energetic contributions of which can be extracted separately, as depicted in Figure 3. The first is oxidation (Figure 3a; Supporting Information eq. S15), in which a trapped oxygen vacancy is filled by a gas-phase oxygen atom, generating two electron holes. The energy of this reaction is the oxygen affinity for a given dopant, $E_{\text {O.dopant }}$ (Supporting Information eq. S18), which depends on the dopant solution energy and the energy of a dopant-oxide-ion vacancy (association) pair, and is thus affected by the amount of local lattice distortion caused by dopant atoms. The second reaction is hydrogenation, by which gas-phase hydrogen is incorporated at oxygen sites far from the dopant, consuming an electron hole (Figure 3b; Supporting Information eq. S16). This reaction, in turn, defines the affinity of the perfect crystal to hydrogen, $E_{\text {H.host }}$ (Supporting Information eq. S19). The third reaction is the energy released when an isolated proton far from any dopants, becomes trapped in the vicinity of a dopant atom, giving the association energy, $E_{\mathrm{as}}$ (Figure $3 \mathrm{c}$ ). The proton trapping site depends on the size of the dopant, suggesting that $E_{\text {as }}$ is mostly determined by the amount of local lattice distortion, all else being equal. The energy of the hydration reaction, $E_{\mathrm{hyd}}$, is given by

$$
E_{\text {hyd }}=E_{\text {O.dopant }}+2 E_{\text {H.host }}+2 E_{\text {as }} \text {. }
$$

By combining and rearranging the energy components of each term on the right-hand side of eq. (6), we obtain the $E_{\text {hyd }}$ in terms of DFT energies, as illustrated in Fig. $3 \mathrm{~d}$. Takahashi et al. ${ }^{31}$ investigated hydration behavior in doped barium zirconates in terms of protonation and oxygen vacancy formation near dopants without considering proton-dopant interactions, and Bjørheim et al. ${ }^{57}$ recently investigated the two parameters $E_{\text {O.dopant }}$ and $E_{\text {H.host }}$ for undoped oxides; in contrast, our analytical framework allows us to consider three energy terms together in the form of $E_{\text {hyd }}$ according to eq. (6).

Each of the energy components contributing to $E_{\text {hyd }}$ in Figure $3 \mathrm{~d}$ were determined from the DFT calculations with the Fermi energy level set to the top of the valence band, and are summarized in Table 2, with literature data included for comparison. ${ }^{31,35,36}$ Although absolute values of our calculated $E_{\text {as }}$ appear to differ systematically from literature, presumably because of the use of different models, the overall trends agree well. 
The various energies and the relationships between them are illustrated schematically in Figure 4, revealing the quantitative relationship between the hydration energies and the energies of the reactions. The left-hand side of Figure 4 shows the three main states during the hydration process. At the top is the initial state, i.e., after acceptor doping, with the introduced oxygen vacancy occupying the most stable site, namely adjacent to the trivalent dopant. The middle structure corresponds to the virtual oxidation step, taken as a reference state, and acts to stabilize the system (yellow arrows). Hydrogenation slightly destabilizes the system (upward pointing blue arrows), and the energies here also depend only on the nature of the host material, not on the dopant. The final structure at the bottom-left of Figure 4 is after proton trapping (strong interaction between the proton and dopant), whose energy sharply reduces the total energy (red arrows), resulting in some cases in a strongly negative $E_{\text {hyd }}$.

Identifying these relationships enables effective strategies for enhancing proton conduction in oxides to be developed. In order for proton uptake to occur at all, it is necessary that the hydration energy of the material (green arrows in Figure 4) be more negative than the oxygen affinity (yellow arrows in Figure 4), i.e., $\left|E_{\text {hyd }}\right|>\left|E_{\text {O.dopant }}\right|$. In such a case, it is energetically more favorable for the oxygen vacancies to be occupied by hydroxyl groups (implying proton incorporation) than with oxide ions (implying creation of electronic holes). A strongly negative hydration energy necessary for producing large proton concentrations will result when the proton-dopant association is strong (large red arrows). Such a relationship is observed in Figure 2a. However, a large negative trapping energy implies that the incorporated protons will have low mobility, and thus a large $\left|E_{\text {as }}\right|$ is undesirable. The preferred scenario is one in which the magnitude of the hydration energy is large (larger in magnitude than $E_{\text {O.dopant }}$ ) because the energy of the initial state, that with oxide-ion vacancies, is high. In that case, even a small $E_{\mathrm{as}}$, as long as it is large enough to overcome the hydrogen affinity, $E_{\mathrm{H} \text {.host }}$ (blue arrows in Figure 4), can result in a system with a large $E_{\text {hyd. }}$. Ultimately, what is most desirable is a material with a large hydration energy for proton incorporation in the absence of trapping. The hypothetical hydration energy for creating such trap-free protons, $E_{\text {hyd.free, }}$ is simply the sum of $E_{\text {O.dopant }}$ (yellow arrows) and $2 E_{\text {H.host }}$ (blue arrows)

$$
E_{\text {hyd.free }}=E_{\text {O.dopant }}+2 E_{\text {H.host }},
$$

which is shown in Figure 4 as purple arrows. From Eqs. (7) and (8), therefore, it is evident that there are only two independent materials parameters, $E_{\text {as }}$ and $E_{\text {O.dopant, }}$, that can be tuned by dopant selection to produce a faster proton conductor. Moreover, because it is the mobile protons not trapped in the vicinity of dopant atoms that mainly contribute to the proton conductivity, we can predict that a material with a large negative $E_{\text {hyd.free }}$ and hence large oxygen affinity will display high protonic conductivity. Because $E_{\text {H.host }}$ is independent of the type of dopant, and is thus a constant for a given host material, eq. (8) further shows that $E_{\text {O.dopant }}$ can serve as a proxy for $E_{\text {hyd.free }}$ in order to identify systems with high concentrations of mobile protons, i.e., materials with strongly negative hydration energies, and minimal proton-dopant trapping, from which to make good proton conductors. 
A plot of association energy and oxygen affinity against dopant ion radius is shown in Figure $2 \mathrm{~b}$ for all dopants. Oxygen affinities (yellow line) generally fall and then rise with increasing dopant ion radius, with the most negative value occurring for Lu. Here, In is an outlier. This behavior appears to be related to the fact that In is the only one of the dopants to adopt a brownmillerite structure, $\mathrm{BaInO}_{2.5}$ (in which oxygen vacancies are completely ordered in alternating layers so that In is in both 4- and 6-fold coordination), when completely replacing the B-site cations. The association energies (red line), calculated from energies of the most strongly trapping sites, reveal a trend that is almost precisely the opposite to that of oxygen affinity, peaking at an ionic radius of around 0.89 $\AA$. Furthermore, for dopants with small ionic radii, i.e., dopants from Sc to Lu, the proton is most strongly trapped on the $1^{\text {st }} \mathrm{NP}$ site, whereas for $\mathrm{Er}$ and larger, the proton is most strongly trapped on the $2^{\text {nd }} \mathrm{NP}$ site. A rise then fall in computed dopant-proton association energies, accompanied by a change in the position of the strongest proton trapping site, has also been observed by Bjorketun et al. ${ }^{35}$

The inverse relationship between $E_{\text {as }}$ and $E_{\text {O.dopant }}$ is directly seen in Figure 2c, where again In emerges as an outlier. The data further reveal that for a given oxygen affinity, proton trapping is apparently less severe when the trap site is the $2^{\text {nd }} \mathrm{NP}$ position as opposed to the $1^{\text {st }} \mathrm{NP}$ position. Although the association and oxidation reactions can be written separately, the data suggest that it may not be possible to manipulate these energy terms independently by selecting different dopants, as both depend on the dopant incorporation energy (Figs. 3a and 3c). With respect to proton transport energetics, the ideal material can be anticipated to have a strongly negative $E_{\text {hyd.free }}$ and a minimally negative $E_{\text {as. }}$. Both conditions, in turn, are predicted to be met when the oxygen affinity is strongly negative, according to Eq. (8) for $E_{\text {hyd.free }}$ and from the correlations revealed in Figure $2 \mathrm{c}$ for $E_{\text {as }}$. Thus, $E_{\text {O.dopant }}$ emerges as the most reliable predictor of protonic conductivity, and our results suggest that Er, followed by $\mathrm{Lu}$, should be the dopant that provides the highest proton conductivity. The aberrant behavior of In, an instance in which $E_{\text {as }}$ cannot be predicted from $E_{\text {O.dopant }}$, provides an important test-case for determining the relative importance of these two energy terms to the overall transport.

3.2 Experimental validation of the theoretical results. A complementary experimental study of the impact of dopant selection on conductivity to evaluate the validity of our theoretical framework was performed using electrochemical impedance spectroscopy. Although a few experimental studies have attempted to identify the dopant that produces the highest conductivity in barium zirconate, ${ }^{39,58}$ challenges regarding processing, in particular barium loss, microstructural inhomogeneities, and extent of hydration, can result in substantial differences in measured conductivities even for materials with nominally identical composition. ${ }^{2,11,59}$ Recognition of these challenges motivated the new measurements performed here. Dopants whose ionic radii are close to $0.89 \AA$ in 6-fold coordination ( $\mathrm{Sc}, \mathrm{In}, \mathrm{Lu}, \mathrm{Er}, \mathrm{Y}$, and Gd) were selected, and the dopant concentration was fixed at $20 \mathrm{at} \%$, an optimal value beyond which the conductivity no longer increases. ${ }^{60-62}$ The results for $\mathrm{BaZr}_{0.8} \mathrm{Y}_{0.2} \mathrm{O}_{3}$ have been reported previously. ${ }^{6}$

Bulk proton conductivities determined using impedance spectroscopy over a wide temperature range, plotted in Figure 5a, are very much in agreement with the computational prediction, with $\mathrm{Er}$ and Lu dopants producing the highest conductivity materials. Similar to what has been reported in the literature, ${ }^{39,58}$ the proton conductivity 
first increases then decreases with the radius of the ionic dopant over the range spanned from $\mathrm{Sc}$ to $\mathrm{Gd}$, as seen in Figure $5 \mathrm{~b}$ for a representative temperature of close to $350{ }^{\circ} \mathrm{C}$ for all dopants. Some disagreement, however, is evident in the vicinity of the optimal dopant radius (results for $150^{\circ} \mathrm{C}$ and $110^{\circ} \mathrm{C}$ are plotted in Supporting Information Figure S5). For example, Imashuku et al. ${ }^{39}$ found Y to be far superior to Er, whereas Gilardi et al. ${ }^{58}$ found $Y$ to be only somewhat superior to Lu. Overall, the high conductivity in this narrow range of dopant ion radii can be understood based on our computational framework to result from the combination of a strong oxygen affinity and a weak proton association energy, with experimental factors likely impacting the precise conductivity values when the dopant-induced differences are small.

Of the two energy terms, the oxygen affinity, which serves as a proxy for the hydration energy (Eqs. (7) and (8)), has the more systematic impact on conductivity. This is evident from a comparison of Figures $5 \mathrm{c}$ and $5 \mathrm{~d}$; in Figure 5c, the conductivity increases monotonically with increasingly negative $E_{\text {O.dopant }}$ for a given proton trapping position ( $1^{\text {st }}$ or $2^{\text {nd }} \mathrm{NP}$ ), even in the case of In, whereas in Figure $5 \mathrm{~d}$ In lies well outside the trend exhibited by the other dopants. Significantly, In is found to be an outlier in the experimental results not only of the present study but also in the literature..$^{8,39,58}$ To date, no explanation for the unusual behavior of this dopant has been provided. Our calculations indicate that a small oxygen affinity for In results in low levels of hydration, as experimentally observed. ${ }^{8}$ Thus, despite relatively weak trapping, the conductivity is low. The anomalous behavior of In in Figure $5 \mathrm{~b}$ further reveals that ionic radius alone is an unsatisfactory predictor of conductivity.

The results above show that, overall, the oxygen affinity of the strongest proton trapping site provides the most reliable measure for predicting the degree of proton conduction in these oxides. The reason for this is that oxygen affinity, $E_{\text {O.dopant, }}$ is directly related to the hypothetical hydration energy, $E_{\text {hyd.free, for creating trap-free protons, as }}$ shown by eq. (8), and thus can be used in its place to identify oxides capable of incorporating high concentrations of mobile protons. As seen in Fig. $3 \mathrm{e}, E_{\text {hyd.free }}$ itself can be broken down into five energy terms, the first and fourth of which only depend on the type of acceptor dopant, and the difference between them is the main parameter impacting on $E_{\text {hyd.free }}$ by a choice of dopant. Importantly, the difference of these two terms are only found in the expression for $E_{\text {O.dopant }}$ (Fig. 3a), and not in those of $E_{\text {hyd }}$ (Fig. $3 d$ ) or $E_{\text {as }}$ (Fig. 3c). Similar to $E_{\text {as }}, E_{\text {hyd }}$ does not account for the outlier In (Fig. S6). The appropriateness of using oxygen affinity as the primary predictor of proton conductivity (once the most stable proton trapping site has been identified) is evidenced by the monotonic relationship between $\sigma_{\mathrm{H}}$ and $E_{\text {O.dopant }}$ in Fig. $5 \mathrm{c}$. As these correlations are not limited to a particular type of crystal structure or composition of the host crystal, we expect them to apply also to the characterization and search for other proton-conducting oxide systems. Determining the physical reason for why proton conductivity appears optimal when the first- and second-nearest neighbor association energies are closest to one another is also an interesting and important task.

\section{Conclusions}

Hydration energies $\left(E_{\text {hyd }}\right)$, proton-dopant association energies $\left(E_{\text {as }}\right)$, oxygen affinities $\left(E_{\mathrm{O} \text {,dopant }}\right)$, and hydrogen affinities $\left(E_{\mathrm{H}, \text { host }}\right)$, were derived for $\mathrm{SC}^{-}, \mathrm{In}-$, Lu- ,

Er-, $\mathrm{Y}-, \mathrm{Gd}-$, and $\mathrm{Eu}-$ doped $\mathrm{BaZrO}_{3}$ from DFT calculations. Hydration energy is 
related to the other energies according to $E_{\mathrm{hyd}}=E_{0 . \text { dopant }}+2 E_{\mathrm{H} . h o s t}+2 E_{\mathrm{as}}$. With the exception of In, hydration and association energies are least negative for Er and $\mathrm{Y}$, whose ionic radii are around $0.89-0.9 \AA$, whereas the oxygen affinity of the strongest proton trapping site is most negative for $\mathrm{Lu}$, with an ionic radius of $0.86 \AA$. The results reveal that the compound with highest proton conductivity has the most negative hydration energy and the least negative association energy, in other words, the most negative oxygen affinity. Furthermore, with the exception of In, the doped barium zirconates display a strong correlation between proton trapping energy and oxygen affinity. Impedance spectroscopy measurements of proton conductivities in $20 \mathrm{at} \% \mathrm{Sc}^{-}$, In-, $\mathrm{Lu}-, \mathrm{Er}-$, and $\mathrm{Gd}$-doped $\mathrm{BaZrO}_{3}$ showed that the more negative the oxygen affinity, the higher the proton conductivity at $350^{\circ} \mathrm{C}$, providing strong support for our theoretical framework. Oxygen affinity was shown to be the best predictor of proton conductivity, and is readily extractable from ab initio calculations. By extending our method to a wide range of oxides, these insights are expected to accelerate the development and design of improved proton-conducting oxides for low- to intermediate-temperature applications.

Supporting Information

The Supporting Information is available free of charge on the ACS Publications website.

Details of the PAW potentials, dynamical stability, defect formation energies, lattice constants, proton sites, hydration and proton-dopant association energies, dopant-oxygen and hydrogen-oxygen affinities, and proton conductivities.

\section{Acknowledgements}

This work was supported by JSPS KAKENHI (15H02287, 16H00891, and JP18H01694), the Iketani Foundation, the Kyushu University Progress 100, and the Japan Science and Technology Agency CREST (JPMJCR18J3). AK acknowledges financial support from JSPS KAKENHI 25106008, 16K06739 and 16H06440, and SMH acknowledges support from the US Department of Energy under award DE-AR0000498. We thank J. Potticary for assistance in the synthesis of Er-doped $\mathrm{BaZrO}_{3}$, and $\mathrm{Dr} \mathrm{K}$. Yamamoto for assistance with silver electrode sputtering. 
Table 1. Energy terms evaluated in this work, and the reactions from which they are calculated, in which $\mathrm{M}$ is a trivalent dopant. The configurations of $\left(\mathrm{M}_{\mathrm{Zr}}^{\prime}-V_{0}^{\bullet \bullet}\right)^{\bullet}$ and $\left(\mathrm{M}_{\mathrm{Zr}}^{\prime}-\mathrm{OH}_{\mathrm{O}}^{\circ}\right)^{\times}$we consider here are the most stable one. The corresponding equations are provided in Supporting Information.

\begin{tabular}{|c|c|c|}
\hline Energy & Reaction (in Kröger-Vink notation) & Eq. \\
\hline$E_{\text {hyd }}$ & $\left(\mathrm{M}_{\mathrm{Zr}}^{\prime}-\mathrm{O}_{\mathrm{O}}^{\times}\right)^{\prime}+\left(\mathrm{M}_{\mathrm{Zr}}^{\prime}-V_{0}^{\bullet \bullet}\right)^{\bullet}+\mathrm{H}_{2} \mathrm{O}_{(g)} \rightarrow 2\left(\mathrm{M}_{\mathrm{Zr}}^{\prime}-\mathrm{OH}_{\mathrm{O}}^{\bullet}\right)^{\times}$ & S13 \\
\hline$E_{\text {as }}$ & $\left(\mathrm{M}_{\mathrm{Zr}}^{\prime}-\mathrm{O}_{0}^{\times}\right)^{\prime}+\left(\mathrm{Zr}_{\mathrm{Zr}}^{\times}-\mathrm{OH}_{0}^{\bullet}\right)^{\bullet} \rightarrow\left(\mathrm{M}_{\mathrm{Zr}}^{\prime}-\mathrm{OH}_{0}^{\bullet}\right)^{\times}+\left(\mathrm{Zr}_{\mathrm{Zr}}^{\times}-\mathrm{O}_{\mathrm{O}}^{\times}\right)^{\times}$ & S14 \\
\hline$E_{\mathrm{O}, \mathrm{dopant}}$ & $\left(\mathrm{M}_{\mathrm{Zr}}^{\prime}-V_{0}^{\bullet \bullet}\right)^{\bullet}+\frac{1}{2} \mathrm{O}_{2} \rightarrow\left(\mathrm{M}_{\mathrm{Zr}}^{\prime}-\mathrm{O}_{\mathrm{O}}^{\times}\right)^{\prime}+2 \mathrm{~h}^{\bullet}$ & S20 \\
\hline$E_{\text {H.host }}$ & $\left(\mathrm{Zr}_{\mathrm{Zr}}^{\times}-\mathrm{O}_{\mathrm{O}}^{\times}\right)^{\times}+\frac{1}{2} \mathrm{H}_{2}+\mathrm{h}^{\bullet} \rightarrow\left(\mathrm{Zr}_{\mathrm{Zr}}^{\times}-\mathrm{OH}_{0}^{\bullet}\right)^{\bullet}$ & S21 \\
\hline$E_{\text {hyd.free }}$ & $\begin{array}{c}\left(\mathrm{M}_{\mathrm{Zr}}^{\prime}-V_{\mathrm{O}}^{\bullet}\right)^{\bullet}+2\left(\mathrm{Zr}_{\mathrm{Zr}}^{\times}-\mathrm{O}_{\mathrm{O}}^{\times}\right)^{\times}+\mathrm{H}_{2} \mathrm{O} \\
\rightarrow\left(\mathrm{M}_{\mathrm{Zr}}^{\prime}-\mathrm{O}_{\mathrm{O}}^{\times}\right)^{\prime}+2\left(\mathrm{Zr}_{\mathrm{Zr}}^{\times}-\mathrm{OH}_{0}^{\bullet}\right)^{\bullet}\end{array}$ & S22 \\
\hline
\end{tabular}


Table 2. Hydration energies $\left(E_{\text {hyd }}\right)$, oxygen affinities $\left(E_{\text {O.dopant }}\right)$, proton-dopant association energies $\left(E_{\mathrm{as}}\right)$, and hydration energies for creating trap-free protons $\left(E_{\text {hyd.free }}\right)$ from DFT calculations. $E_{\text {H.host }}=0.050 \mathrm{eV}$ in all cases.

\begin{tabular}{|c|c|c|c|c|c|}
\hline Dopant & $E_{\text {hyd }} / \mathrm{eV}$ & $E_{\text {O.dopant }} / \mathrm{eV}$ & $E_{\mathrm{as}}(1 \mathrm{st}) / \mathrm{eV}$ & $E_{\mathrm{as}}(2 \mathrm{nd}) / \mathrm{eV}$ & $E_{\text {hyd.free }} / \mathrm{eV}$ \\
\hline \multirow[t]{3}{*}{$\mathrm{Sc}$} & -0.934 & -0.444 & -0.296 & -0.047 & -0.342 \\
\hline & -0.89 & & $-0.239^{\#}$ & $+0.024^{\#}$ & \\
\hline & $-0.69^{*}$ & & & & \\
\hline \multirow[t]{3}{*}{ In } & -0.652 & -0.350 & -0.201 & -0.092 & -0.250 \\
\hline & $-0.57^{\mathbb{I}}$ & & $-0.166^{\#}$ & $-0.016^{\#}$ & \\
\hline & $-0.31^{*}$ & & & & \\
\hline \multirow[t]{2}{*}{$\mathrm{Lu}$} & -0.882 & -0.534 & -0.224 & -0.108 & -0.435 \\
\hline & $-0.38^{*}$ & & & & \\
\hline $\mathrm{Er}$ & -0.798 & -0.520 & -0.188 & -0.189 & -0.421 \\
\hline \multirow[t]{3}{*}{$\mathrm{Y}$} & -0.820 & -0.487 & -0.196 & -0.216 & -0.388 \\
\hline & -0.60 & & $-0.155^{\#}$ & $-0.166^{\#}$ & \\
\hline & $-0.22^{*}$ & & & & \\
\hline \multirow[t]{2}{*}{$\mathrm{Gd}$} & -0.844 & -0.366 & -0.204 & -0.289 & -0.267 \\
\hline & $-0.51^{\top}$ & & $-0.155^{\#}$ & $-0.202^{\#}$ & \\
\hline $\mathrm{Eu}$ & -0.872 & -0.276 & -0.228 & -0.348 & -0.177 \\
\hline
\end{tabular}

\# Data from the graph of Fig. 4 in Ref. 35.

I Ref. 36

${ }^{*}$ Ref. 31 
(a)

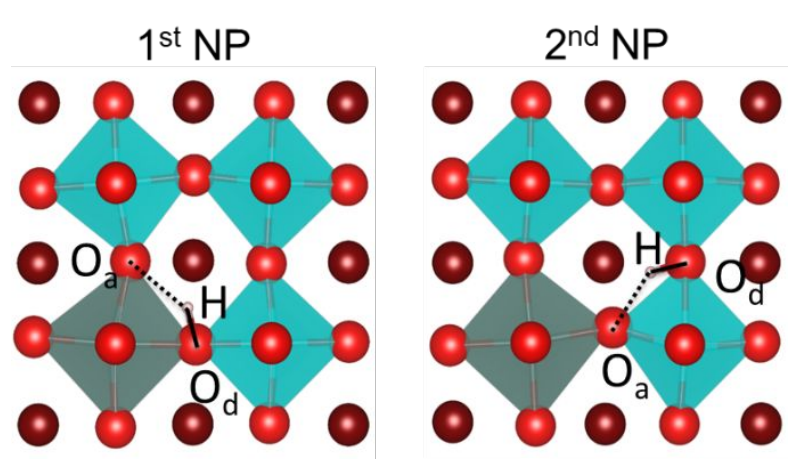

(b)

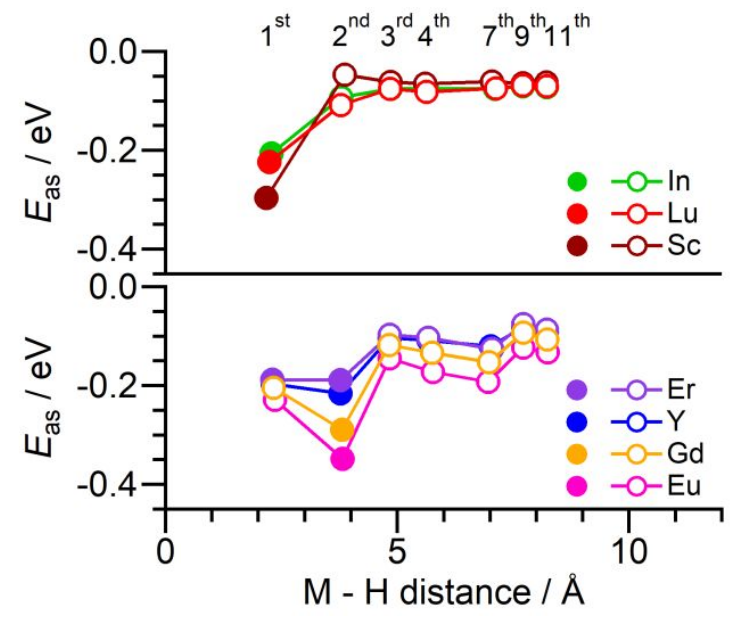

Figure 1. (a) Schematic diagrams of local structures around a dopant atom and proton on $1^{\text {st }}$ and $2^{\text {nd }}$ nearest proton (NP) sites. (b) Corresponding proton (H)-dopant (M) association energies plotted as a function of $\mathrm{M}-\mathrm{H}$ distance corresponding to different proton sites (from $1^{\text {st }} \mathrm{NP}$ site to $11^{\text {th }} \mathrm{NP}$ site), split into two groups: $1^{\text {st }} \mathrm{NP}$ site trapping (top) and $2^{\text {nd }} \mathrm{NP}$ site trapping (bottom). Full circles indicate the lowest energy for that dopant species, and open circles all other energies. 
(a)

(b)
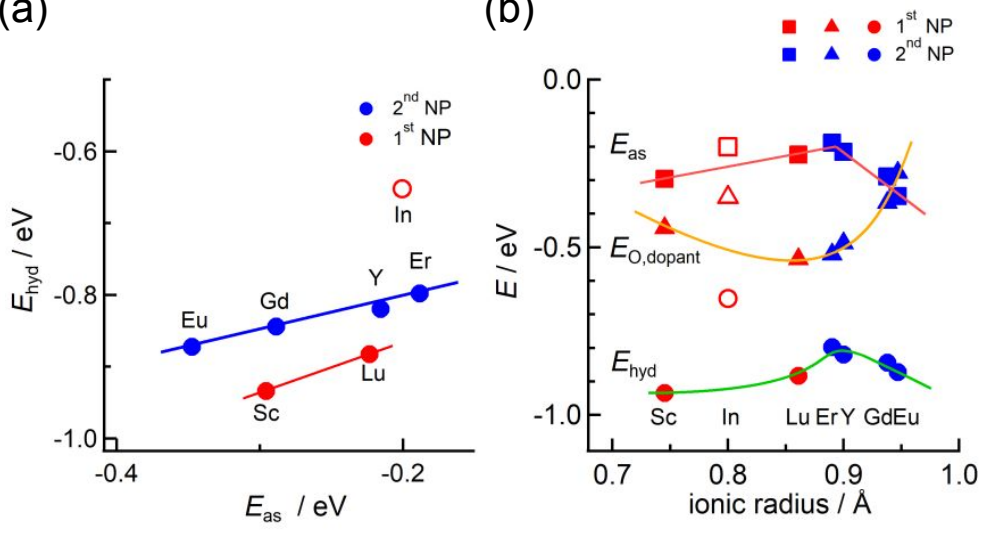

(C)

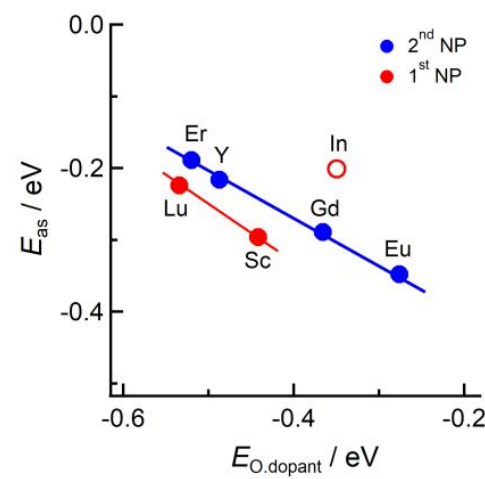

Figure 2. (a) Hydration energy ( $\left.E_{\text {hyd }}\right)$ vs proton-dopant association energy $\left(E_{\text {as }}\right)$; (b) energies $E_{\text {as }}, E_{\text {hyd }}$, and oxygen affinity $\left(E_{\text {O.dopant }}\right)$ vs ionic radius of dopant; and (c), $E_{\text {as }}$ vs $E_{\text {O.dopant }}$. Energies for $1^{\text {st }}$ and $2^{\text {nd }}$ nearest proton (NP) sites from the dopant atom are indicated in each case. 


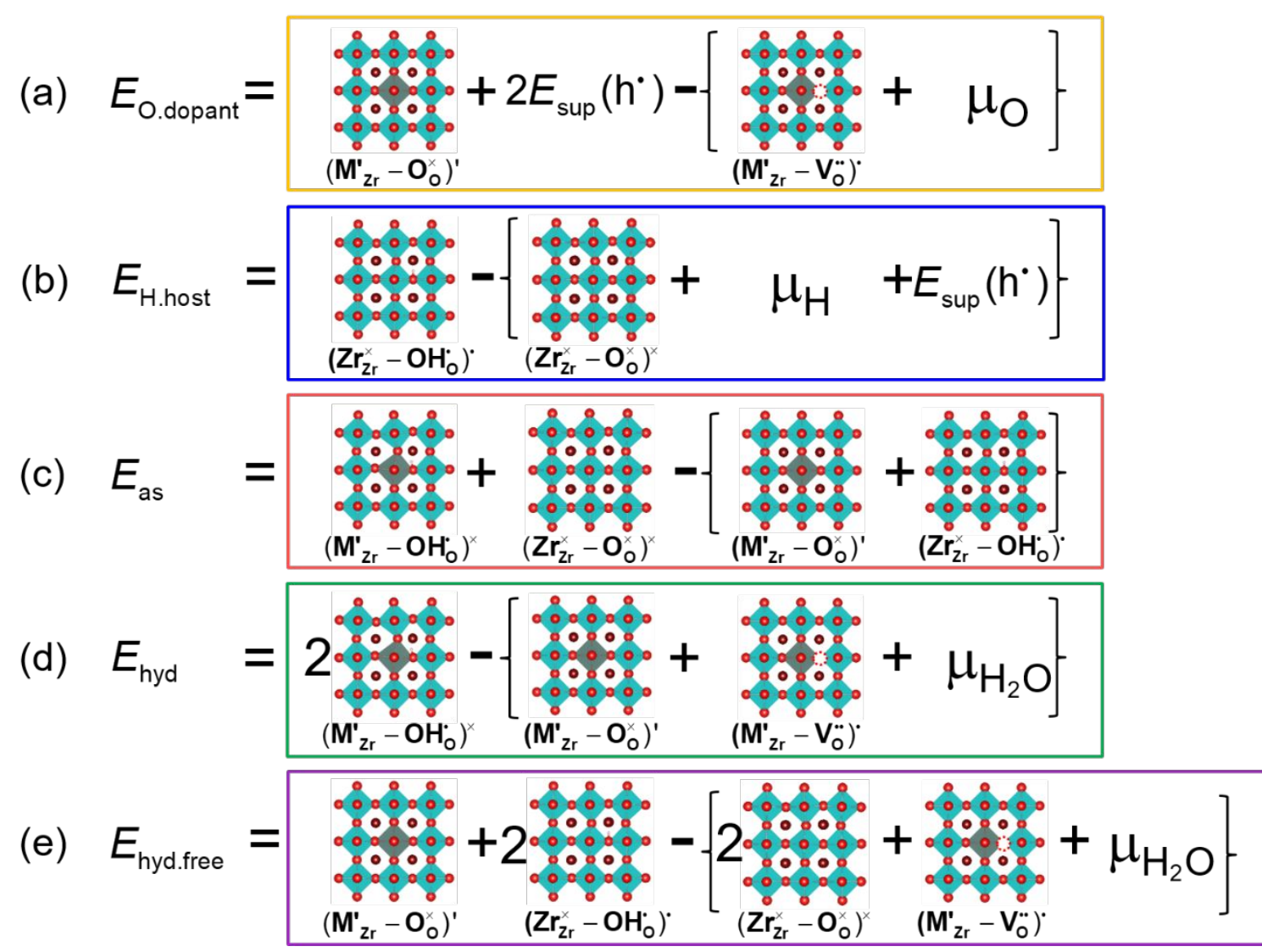

Figure 3. Schematic representations of energy terms: (a) Oxygen affinity, $E_{\mathrm{O} \text {,dopant, }}$ (b) hydrogen affinity, $E_{\mathrm{H} \text {.host }}$, (c) association energy, $E_{\mathrm{as}}$, (d) hydration energy, $E_{\text {hyd }}$, and (e) hydration energy of free (non-trapped) protons, $E_{\text {hyd,free }}$. The definition of each energy is given in the methodology section. The colors of the right-hand side boxes correspond to the arrows representing calculated energy values in Figure 4. 


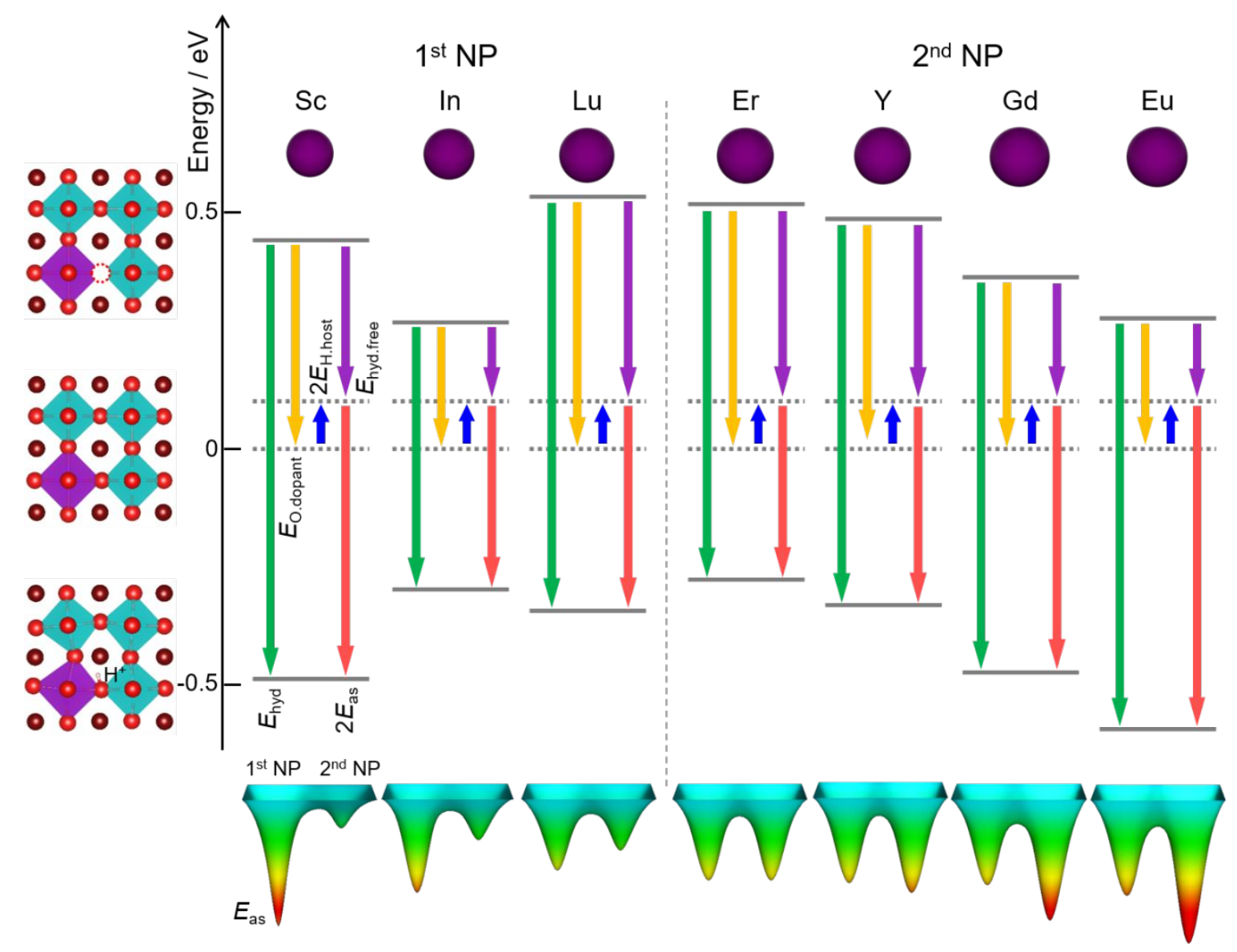

Figure 4. Energy diagrams for proton-conducting acceptor-doped barium zirconates. Hydration energies $\left(E_{\text {hyd }}\right)$, oxygen affinities $\left(E_{\text {O.dopant }}\right)$, hydrogen affinities $\left(E_{\text {H.host }}\right)$ of the undoped (perfect) crystal, and proton-dopant association energies $\left(E_{\text {as }}\right)$ are shown as green, yellow, blue, and red arrows, respectively. Dopants $\mathrm{M}=\mathrm{Sc}$, In, Lu, Er, Y, Gd, and $\mathrm{Eu}$ are shown in order of increasing ionic radius from left to right. The contour plots at the bottom visualize the proton-dopant association energy wells for a proton occupying $1^{\text {st }}$ and $2^{\text {nd }}$ nearest proton (NP) sites to the dopant. Red portions indicate deep proton trapping. 


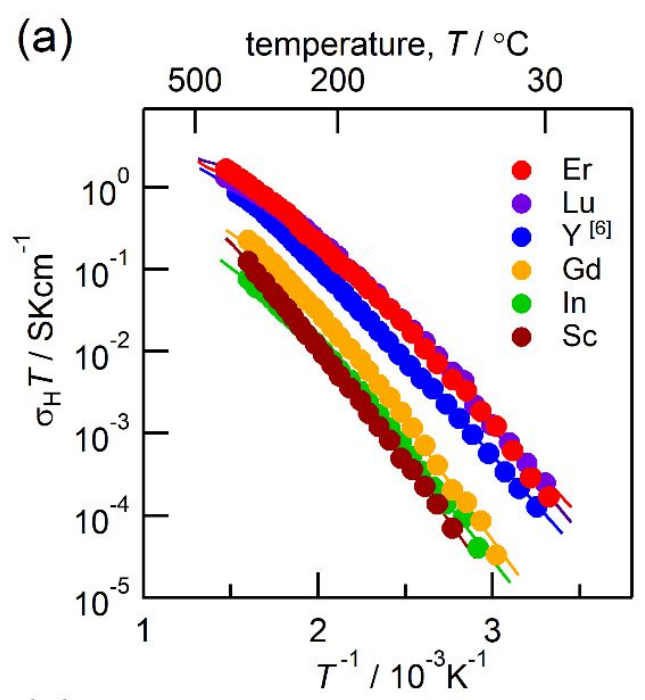

(b)

(c)
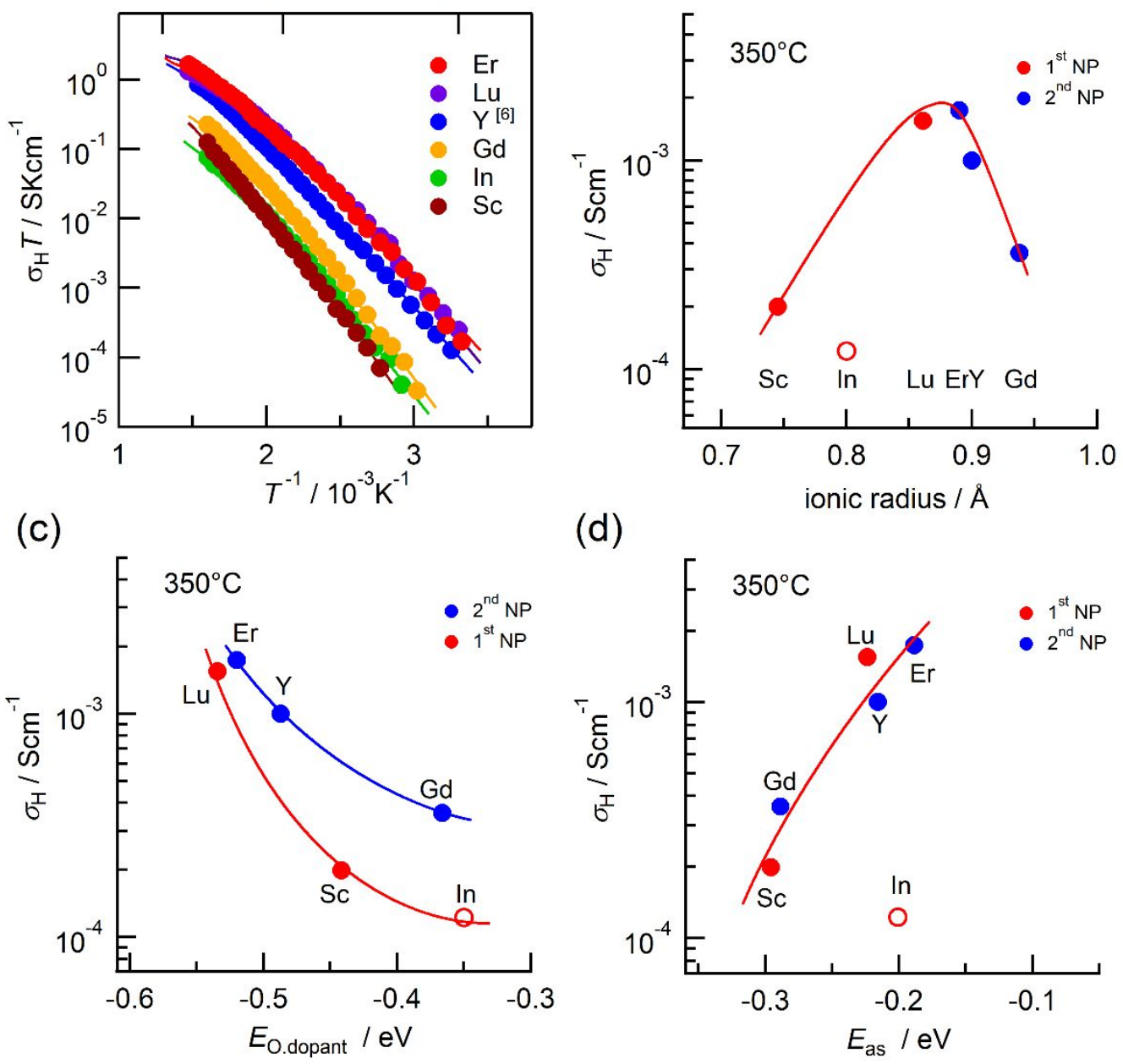

(d)

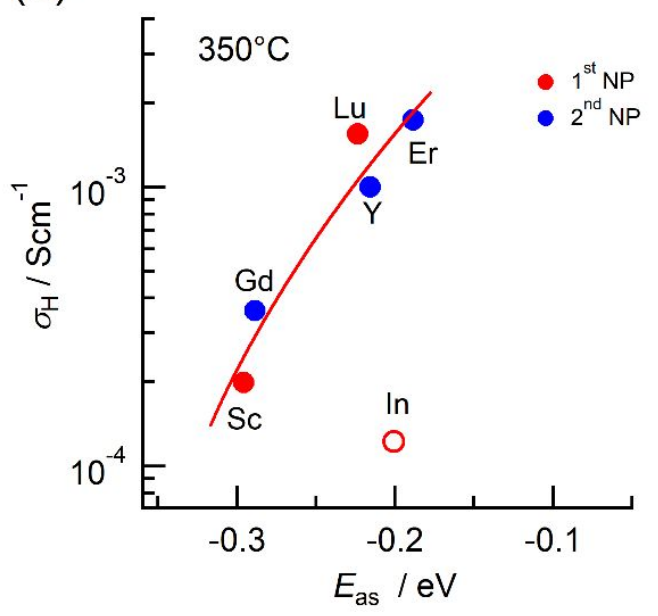

Figure 5. Experimental bulk proton conductivities, $\sigma_{\mathrm{H}}$, in 20 at\% Sc-, In-, Lu-, Er-, Y-, and Gd-doped barium zirconates against (a) temperature, (b) ionic radius, (c) oxygen affinity, $E_{\text {O.dopant }}$, and (d) proton-dopant association energy, $E_{\mathrm{as}}$. Values for $\mathrm{Y}-\mathrm{BaZrO}_{3}$ were taken from ref. 6 . 


\section{References}

1. Kreuer, K. D., Aspects of the formation and mobility of protonic charge carriers and the stability of perovskite-type oxides. Solid State Ionics 1999, 125 (1-4), 285-302.

2. Yamazaki, Y.; Hernandez-Sanchez, R.; Haile, S. M., High total proton conductivity in large-grained yttrium-doped barium zirconate. Chemistry of Materials 2009, 21, $2755-2762$.

3. Hyodo, J.; Kitabayashi, K.; Hoshino, K.; Okuyama, Y.; Yamazaki, Y., Fast and Stable Proton Conduction in Heavily Scandium-Doped Polycrystalline Barium Zirconate at Intermediate Temperatures. Advanced Energy Materials 2020, 10, 2000213.

4. Kreuer, K. D., Proton-conducting oxides. Annual Review of Materials Research 2003, 33, 333-359.

5. Norby, T.; Widerøe, M.; Glöckner, R.; Larring, Y., Hydrogen in oxides. Dalton Trans. 2004, 0, 3012-3018.

6. Yamazaki, Y.; Blanc, F.; Okuyama, Y.; Buannic, L.; Lucio-Vega, J. C.; Grey, C. P.; Haile, S. M., Proton trapping in yttrium-doped barium zirconate. Nature Materials 2013, 12, 647-651.

7. Schober, T.; Bohn, H. G., Water vapor solubility and electrochemical characterization of the high temperature proton conductor BaZr0.9Y0.1O2.95. Solid State Ionics 2000, 127 (3-4), 351-360.

8. Kreuer, K. D.; Adams, S.; Munch, W.; Fuchs, A.; Klock, U.; Maier, J., Proton conducting alkaline earth zirconates and titanates for high drain electrochemical applications. Solid State Ionics 2001, 145 (1-4), 295-306.

9. Yamazaki, Y.; Babilo, P.; Haile, S. M., Defect Chemistry of Yttrium-Doped Barium Zirconate: A Thermodynamic Analysis of Water Uptake. Chemistry of Materials 2008, 20 (20), 6352-6357.

10. Kjolseth, C.; Wang, L.; Haugsrud, R.; Norby, T., Determination of the enthalpy of hydration of oxygen vacancies in Y-doped $\mathrm{BaZrO} 3$ and $\mathrm{BaCeo}(3)$ by TG-DSC. Solid State Ionics 2010, 181, 1740-1745.

11. Yamazaki, Y.; Yang, C. K.; Haile, S. M., Unraveling the defect chemistry and proton uptake of yttrium-doped barium zirconate. Scripta Materialia 2011, 65 (2), 102-107.

12. Kreuer, K. D.; Dippel, T.; Baikov, Y. M.; Maier, J., Water solubility, proton and oxygen diffusion in acceptor doped $\mathrm{BaCeO} 3$ : A single crystal analysis. Solid State Ionics 1996, 86-8, 613-620.

13. Ricote, S.; Bonanos, N.; Caboche, G., Water vapour solubility and conductivity study of the proton conductor $\mathrm{BaCe}(0.9-\mathrm{x}) \mathrm{ZrxY} 0.1 \mathrm{O}(3-\delta)$. Solid State Ionics 2009, 180 (14-16), 990-997.

14. Oishi, M.; Akoshima, S.; Yashiro, K.; Sato, K.; Mizusaki, J.; Kawada, T., Defect structure analysis of $\mathrm{B}$-site doped perovskite-type proton conducting oxide $\mathrm{BaCeO} 3$ Part 1: The defect concentration of $\mathrm{BaCe} 0.9 \mathrm{M} 0.1 \mathrm{O} 3-\delta(\mathrm{M}=\mathrm{Y}$ and $\mathrm{Yb})$. Solid State Ionics 2009, 180 (2-3), 127-131.

15. Wang, Y.; Chesnaud, A.; Bevillon, E.; Yang, J.; Dezanneau, G., Synthesis, structure and protonic conduction of BaSn0.875M0.12503- $\delta(\mathrm{M}=\mathrm{Sc}, \mathrm{Y}$, In and $\mathrm{Gd})$. Int $J$ Hydrogen Energ 2011, 36 (13), 7688-7695.

16. Wang, Y.; Chesnaud, A.; Bevillon, E.; Dezanneau, G., Properties of Y-doped BaSnO3 proton conductors. Solid State Ionics 2012, 214, 45-55. 
17. Bjorheim, T. S.; Rahman, S. M.; Eriksson, S. G.; Knee, C. S.; Haugsrud, R., Hydration thermodynamics of the proton conducting oxygen-deficient perovskite series BaTi1-xMxO3-x/2 with $\mathrm{M}=$ In or Sc. Inorg Chem 2015, 54 (6), 2858-65.

18. Zohourian, R.; Merkle, R.; Maier, J., Proton uptake into the protonic cathode material $\mathrm{BaCo} 0.4 \mathrm{Fe} 0.4 \mathrm{Zr} 0.2 \mathrm{O} 3-\delta$ and comparison to protonic electrolyte materials. Solid State Ionics 2017, 299, 64-69.

19. Zohourian, R.; Merkle, R.; Raimondi, G.; Maier, J., Mixed-Conducting Perovskites as Cathode Materials for Protonic Ceramic Fuel Cells: Understanding the Trends in Proton Uptake. Advanced Functional Materials 2018, 28 (35), 1801241.

20. Yajima, T.; Iwahara, H., Studies on behavior and mobility of protons in doped perovskite-type oxides: (I) In situ measurement of hydrogen concentration in $\mathrm{SrCe} 0.95 \mathrm{Yb0.0503}$ _ at high temperature. Solid State lonics 1992, 50, 281-286.

21. Okuyama, Y.; Isa, K.; Lee, Y. S.; Sakai, T.; Matsumoto, H., Incorporation and conduction of proton in $\mathrm{SrCe} 0.9-\mathrm{xZrxY} 0.1 \mathrm{O} 3-\delta$. Solid State Ionics 2015, 275 , 35-38.

22. Okuyama, Y.; Kozai, T.; Sakai, T.; Matsuka, M.; Matsumoto, H., Proton transport properties of $\mathrm{La} 0.9 \mathrm{M} 0.1 \mathrm{YbO}-\delta(\mathrm{M}=\mathrm{Ba}, \mathrm{Sr}, \mathrm{Ca}, \mathrm{Mg})$. Electrochimica Acta 2013, 95, 54-59.

23. Okuyama, Y.; Ikeda, S.; Sakai, T.; Matsumoto, H., Incorporation of a proton into La0.9Sr0.1(Yb1-xMx)O3- $\delta(\mathrm{M}=\mathrm{Y}$, In). Solid State Ionics 2014, 262, 865-869.

24. Okuyama, Y.; Yamaguchi, T.; Matsunaga, N.; Sakai, G., Proton Conduction and Incorporation into La1-xBaxYb0.5In0.5O3- $\delta$. Mater. Trans. 2018, 59 (1), 14-18.

25. Farlenkov, A. S.; Putilov, L. P.; Ananyev, M. V.; Antonova, E. P.; Eremin, V. A.; Stroeva, A. Y.; Sherstobitova, E. A.; Voronin, V. I.; Berger, I. F.; Tsidilkovski, V. I.; Gorelov, V. P., Water uptake, ionic and hole transport in La 0.9 Sr 0.1 ScO 3- $\delta$. Solid State Ionics 2017, 306, 126-136.

26. Larring, Y.; Norby, T., Protons in rare earth oxides. Solid State Ionics 1995, 77, 147151.

27. Bjorheim, T. S.; Besikiotis, V.; Haugsrud, R., Hydration thermodynamics of pyrochlore structured oxides from TG and first principles calculations. Dalton Trans 2012, 41 (43), 13343-51.

28. Haugsrud, R.; Norby, T., Proton conduction in rare-earth ortho-niobates and ortho-tantalates. Nature Materials 2006, 5 (3), 193-196.

29. Bjorheim, T. S.; Kotomin, E.; Maier, J., Hydration entropy of BaZrO3 from first principles phonon calculations. J Mater Chem A 2015, 3, 7639-7648.

30. Loken, A.; Saeed, S. W.; Getz, M. N.; Liu, X.; Bjorheim, T. S., Alkali metals as efficient A-site acceptor dopants in proton conducting BaZrO3. J Mater Chem A 2016, 4 (23), 9229-9235.

31. Takahashi, H.; Yashima, I.; Amezawa, K.; Eguchi, K.; Matsumoto, H.; Takamura, H.; Yamaguchi, S., First-Principles Calculations for the Energetics of the Hydration Reaction of Acceptor-Doped BaZrO3. Chemistry of Materials 2017, 29, 1528-1526.

32. Takahashi, H.; Oikawa, I.; Takamura, H., Atomistic Insight into the Correlation among Oxygen Vacancies, Protonic Defects, and the Acceptor Dopants in Sc-Doped BaZrO3 Using First-Principles Calculations. Journal of Physical Chemistry C 2018, 122 (12), 6501-6507. 
33. Islam, M. S.; Davies, R. A.; Gales, J. D., Proton migration and defect interactions in the $\mathrm{CaZrO} 3$ orthorhombic perovskite: A quantum mechanical study. Chemistry of Materials 2001, 13 (6), 2049-2055.

34. Islam, M. S.; Slater, P. R.; Tolchard, J. R.; Dinges, T., Doping and defect association in $\mathrm{AZrO} 3(\mathrm{~A}=\mathrm{Ca}, \mathrm{Ba})$ and $\mathrm{LaMO} 3(\mathrm{M}=\mathrm{Sc}, \mathrm{Ga})$ perovskite-type ionic conductors. Dalton Transactions 2004, (19), 3061-3066.

35. Björketun, M. E.; Sundell, P. G.; Wahnström, G., Effect of acceptor dopants on the proton mobility in BaZrO3: A density functional investigation. Physical Review $B$ 2007, 76 (5), 054307.

36. Björketun, M. E.; Sundell, P. G.; Wahnström, G., Structure and thermodynamic stability of hydrogen interstitials in $\mathrm{BaZrO3}$ perovskite oxide from density functional calculations. Faraday Discussions 2007, 134, 247-265.

37. Bevillon, E.; Hermet, J.; Dezanneau, G.; Geneste, G., How dopant size influences the protonic energy landscape in BaSn1-xMxO3-x/2 $(\mathrm{M}=\mathrm{Ga}, \mathrm{Sc}$, In, Y, Gd, La). $J$ Mater Chem A 2014, 2 (2), 460-471.

38. Blanc, F.; Sperrin, L.; Lee, D.; Dervisoglu, R.; Yamazaki, Y.; Haile, S. M.; De Paepe, G.; Grey, C. P., Dynamic Nuclear Polarization NMR of Low-gamma Nuclei: Structural Insights into Hydrated Yttrium-Doped BaZrO3. J Phys Chem Lett 2014, 5 (14), 2431-2436.

39. Imashuku, S.; Uda, T.; Nose, Y.; Taniguchi, G.; Ito, Y.; Awakura, Y., Dependence of Dopant Cations on Microstructure and Proton Conductivity of Barium Zirconate. Journal of the Electrochemical Society 2009, 156 (1), B1-B8.

40. Shannon, R. D., Revised Effective Ionic Radii and Systematic Studies of Interatomie Distances in Halides and Chaleogenides. Acta Cryst. 1976, A32, 751-767.

41. Blöchl, P. E., Projector augmented-wave method. Physical Review B 1994, 50, 17953-17979.

42. Kresse, G.; Joubert, D., From ultrasoft pseudopotentials to the projector augmented-wave method. Physical Review B 1999, 59, 1758-1775.

43. Perdew, J. P.; Burke, K.; Ernzerhof, M., Generalized Gradient Approximation Made Simple. Physical Review Letters 1996, 77, 3865-3868.

44. Kresse, G.; Hafner, J., Ab initio molecular dynamics for liquid metals. Physical Review $B$ 1993, 47, 558-561.

45. Kresse, G.; Furthmüller, J., Efficient iterative schemes for ab initio total-energy calculations using a plane-wave basis set. Physical Review B 1996, 54, 11169-11186.

46. Kresse, G.; Furthmüller, J., Efficiency of ab-initio total energy calculations for metals and semiconductors using a plane-wave basis set. Computational Materials Science 1996, 6, 15-50.

47. Dudarev, S. L.; Savrasov, S. Y.; Humphreys, C. J.; Sutton, A. P., Electron-energy-loss spectra and the structural stability of nickel oxide: An LSDA+U study. Physical Review B 1998, 57, 1505-1509.

48. Jiang, H.; Gomez-Abal, R. I.; Rinke, P.; Scheffler, M., Localized and itinerant states in lanthanide oxides united by GW@LDA+U. Physical Review Letters 2009, 102, $1-4$.

49. Jiang, H.; Rinke, P.; Scheffler, M., Electronic properties of lanthanide oxides from the GW perspective. Physical Review B - Condensed Matter and Materials Physics 2012, $86,1-13$. 
50. Monkhorst, H. J.; Pack, J. D., Special points for Brillouin-zone integrations. Physical Review $B$ 1976, 13, 5188-5192.

51. Levin, I.; Amos, T. G.; Bell, S. M.; Farber, L.; Vanderah, T. A.; Roth, R. S.; Toby, B. H., Phase equilibria, crystal structures, and dielectric anomaly in the BaZrO3CaZrO3 system. Journal of Solid State Chemistry 2003, 175, 170-181.

52. Zhang, S. B.; Northrup, J. E., Chemical potential dependence of defect formation energies in GaAs: Application to Ga self-diffusion. Physical Review Letters 1991, 67, 2339-2342.

53. Kumagai, Y.; Oba, F., Electrostatics-based finite-size corrections for first-principles point defect calculations. Physical Review B - Condensed Matter and Materials Physics 2014, 89.

54. Lany, S.; Zunger, A., Accurate prediction of defect properties in density functional supercell calculations. Model Simul Mater Sc 2009, 17, 084002.

55. Ding, J. L.; Balachandran, J.; Sang, X. H.; Guo, W.; Anchell, J. S.; Veith, G. M.; Bridges, C. A.; Cheng, Y.; Rouleau, C. M.; Poplawsky, J. D.; Bassiri-Gharb, N.; Unocic, R. R.; Ganesh, P., The Influence of Local Distortions on Proton Mobility in Acceptor Doped Perovskites. Chemistry of Materials 2018, 30 (15), 4919-4925.

56. Draber, F. M.; Ader, C.; Arnold, J. P.; Eisele, S.; Grieshammer, S.; Yamaguchi, S.; Martin, M., Nanoscale percolation in doped BaZrO3 for high proton mobility. Nature Materials.

57. Bjørheim, T. S.; Hoedl, M. F.; Merkle, R.; Kotomin, E. A.; Maier, J., Proton, Hydroxide Ion, and Oxide Ion Affinities of Closed-Shell Oxides: Importance for the Hydration Reaction and Correlation to Electronic Structure. The Journal of Physical Chemistry C 2019, 124 (2), 1277-1284.

58. Gilardi, E.; Fabbri, E.; Bi, L.; Rupp, J. L. M.; Lippert, T.; Pergolesi, D.; Traversa, E., Effect of Dopant-Host Ionic Radii Mismatch on Acceptor -Doped Barium Zirconate Microstructure and Proton Conductivity. Journal of Physical Chemistry C 2017, 121 (18), 9739-9747.

59. Yamazaki, Y.; Hernandez-Sanchez, R.; Haile, S. M., Cation non-stoichiometry in yttrium-doped barium zirconate: phase behavior, microstructure and proton conducitivity. Journal of Materials Chemistry 2010, 20, 8158-8166.

60. Babilo, P. Processing and characterization of proton conducting yttrium doped barium zirconate for solid oxide fuel cell applications. Ph.D. thesis, California Institute of Technology, 2007.

61. Fabbri, E.; Pergolesi, D.; Licoccia, S.; Traversa, E., Does the increase in Y-dopant concentration improve the proton conductivity of $\mathrm{BaZ}_{\mathrm{r} 1-x} \mathrm{Y}_{x} \mathrm{O}_{3-\delta}$ fuel cell electrolytes? Solid State Ionics 2010, 181 (21-22), 1043-1051.

62. Han, D. L.; Uda, T., The best composition of an Y-doped $\mathrm{BaZrO}_{3}$ electrolyte: selection criteria from transport properties, microstructure, and phase behavior. $J$ Mater Chem A 2018, 6 (38), 18571-18582.

63. Perrichon, A.; Erik Jedvik Granhed, E. J.; Romanelli, G.; Piovano, A.; Lindman, A.; Hyldgaard, P.; Wahnström, G.; Karlsson, M., Unraveling the Ground-State Structure of $\mathrm{BaZrO}_{3}$ by Neutron Scattering Experiments and First-Principles Calculations. Chemistry of Materials, 2020, 32, 2824-2835.

64. Bilić, A.; Gale, J. D. Ground state structure of $\mathrm{BaZrO}_{3}$ : A comparative first-principles study. Physical Review B, 2009, 79, 174107. 


\section{Table of Contents Graphics}

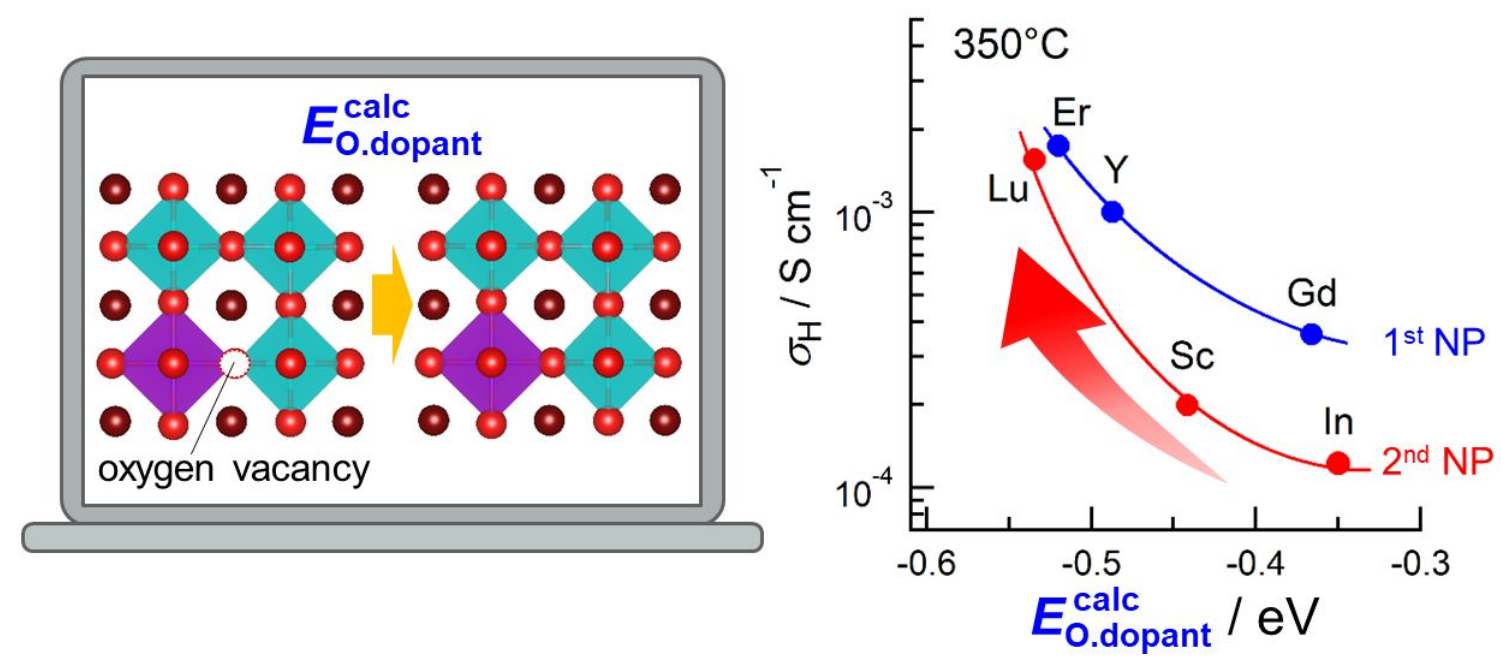

